\title{
Platinum-containing nanocomposites based on humic substances from therapeutic mud
}

\author{
Aleksandrova G.P. ${ }^{1}$, Lesnichaya M.V. ${ }^{1}$, Dolmaa G. ${ }^{2}$, Sukhov B.G. ${ }^{1}$, Regdel D. ${ }^{2}$, \\ Trofimov B.A. ${ }^{1}$ \\ ${ }^{1}$ Favorsky Irkutsk Institute of Chemistry of SB RAS, Irkutsk, Russia, alexa@irioch.irk.ru \\ ${ }^{2}$ Institute of Chemistry and Chemical Technology of Mongolian AS, Ulaan-Baatar, Mongolia \\ Keywords: humic substances, nanoparticles, platinum, therapeutic mud \\ doi: 10.36291/HIT.2019.aleksandrova.102
}

The search for new functional materials is one of the defining characteristics of modern science and technology. Metal nanoparticles, in particular, platinum nanoparticles can possess a wide range of properties that can be used for many practical applications. Platinum has high corrosion resistance and numerous catalytic applications including automotive catalytic converters and petrochemical cracking catalysts.

Previously, first time we studied characteristic of water-soluble silver and gold containing nanocomposites with a variable amount of the metal component based on reducing and stabilizing matrix of humic substances isolated from various deposits in Mongolia [1-2]. The humic substances of therapeutic mud have the greatest reducing and stabilizing ability among the investigated objects [3-4].

Due to potential technological interests of platinum nanoparticles, the synthesis and study of nanoparticles was a very active field of research during last years. In particularly, these studies of nanostructured materials show a strong dependence of their properties on size and shape. For example, the size effect on the catalytical efficiency is known, and the perspective effect on catalysis by the shapes of metal nanoparticles is anticipated and under investigation.

In the present, we report on the result of synthesized Pt-containing nanocomposites based on humic substances. The composition and properties of humic substances isolated from therapeutic mud in Mongolian deposits are established. The methodology of obtaining platinum-containing nanobiocomposites using a matrix of humic substances is described and their composition and structure are characterized by a complex of modern physicochemical methods, such as X-ray energy dispersive spectral microanalysis, infrared spectroscopy, ultraviolet spectroscopy, X-ray diffraction analysis, scanning electron microscopy.

References

1. Lesnichaya M.V. et al. // Doklady Chemistry. 2015. 460(1):13-16.

2. Aleksandrova G.P. et al. // Russian Chemical Bulletin. 2017. 66(1):143-149.

3. Khutsishvili S.S. et al. // J. Thermal Anal. Calorimetry. 2019. 137(4):1181-1188.

4. Dolmaa G., Aleksandrova G.P. Biological activity of humic substances and their nanocomposites. Saarbrücken, 2017. 